\title{
Invited review: resource allocation mismatch as pathway to disproportionate growth in farm animals - prerequisite for a disturbed health
}

\author{
K. Huber ${ }^{\dagger}$ \\ Institute of Animal Science, Faculty of Agricultural Sciences, University of Hohenheim, 70599 Stuttgart, Germany
}

(Received 2 February 2017; Accepted 17 July 2017; First published online 14 August 2017)

\begin{abstract}
The availability of resources including energy, nutrients and (developmental) time has a crucial impact on productivity of farm animals. Availability of energy and nutrients depends on voluntary feed intake and intestinal digestive and absorptive capacity at optimal feeding conditions. Availability of time is provided by the management in animal production. According to the resource allocation theory, resources have to be allocated between maintenance, ontogenic growth, production and reproduction during lifetime. Priorities for these processes are mainly determined by the genetic background, the rearing system and the feeding regimen. Aim of this review was to re-discuss the impact of a proper resource allocation for a long and healthy life span in farm animals. Using the barrel model of resource allocation, resource fluxes were explained and were implemented to specific productive life conditions of different farm animal species, dairy cows, sows and poultry. Hypothetically, resource allocation mismatch neglecting maintenance is a central process, which might be associated with morphological constraints of extracellular matrix components; evidence for that was found in the literature. A potential consequence of this limitation is a phenomenon called disproportionate growth, which counteracts the genetically determined scaling rules for body and organ proportions and could have a strong impact on farm animal health and production.
\end{abstract}

Keywords: maintenance, growth and development, resource allocation, farm animals

\section{Implications}

In modern agriculture, a multitude of farm animal species was genetically selected for high performance. Concomitantly, the requirements of these animals regarding feeding and management were significantly increased. Inadequate feeding and management conditions, often caused by economical pressure, led to physiological limitations of high-yielding farm animals causing a shorten productive life span and the increased prevalence of production-related diseases. This review aimed to highlight critical aspects of modern animal production which are of potential disadvantage for the individual cow, pig or chicken.

\section{Introduction}

Growth and performance in farm animals depend on resources. Resources are necessary to fuel metabolism and vital activities of the body and to serve as substrates to assemble body-own tissues. Overall availability of resources for the

\footnotetext{
${ }^{\dagger}$ E-mail: Korinna.huber@uni-hohenheim.de
}

organism is determined by food intake, gastrointestinal digestion and absorption. After being absorbed by the enterocytes, the allocation of resources within different pathways is a process of major impact for proper growth (=increase in number and size of cells and mass of tissues) and development (=changes in the structure and function of cells and tissues). Proper growth and development are prerequisites for health and performance in farm animals. This review aimed to summarize physiological pathways of resource allocation (see the 'Resources and resource allocation' section) and their limitations (see the 'Limitations of resource allocation' section). Furthermore, the consequences of inadequate resource allocation (resource allocation mismatch) are discussed, which may lead to disproportionate growth (see the 'Disproportionate growth' section) and consequently, to a disturbed health in farm animals.

\section{Resources and resource allocation}

The fundamental resources are energy, nutrients and (developmental) time, the availability of which has a crucial impact on productivity in farm animals. Resource allocation 
is defined as partitioning of available energy and substrates into various essential life processes, and into body structures and tissues (Glazier, 2008). Modeling the resource allocation in maternal rabbit lines revealed that 'generalists' were able to allocate their resources properly to production, reproduction and health under non-adequate environmental conditions, while 'specialists' with high prolificacy were not able to allocate sufficient resources into health and reproduction (Savieto et al., 2015). Furthermore, models in dairy cows and goats were created to answer the question 'Why do animals partition nutrients in the way they do?' and to predict nutrient partitioning (which is a part of resource allocation) (Friggens and Newbold, 2007; Douhard et al., 2014; Puillet et al., 2016). However, creating a new model of resource allocation is beyond the scope of this review. The purpose of this paper is a physiological and mechanistic approach to explain biological pathways of resource allocation and resource allocation mismatch and then to identify pathophysiological consequences of resource allocation mismatch from literature data. It is an attempt to provide an answer to the question: What basal pathways may cause disproportionate growth and thereby, disturbed health? The resource allocation theory can easily be explained using the 'barrel model' (modified after Rauw, 2008, based on the original model of Weiner, 1992) (Figure 1). For this barrel model, it is assumed that an organism can be described as consisting of three funnels for resource uptake and of a barrel representing the body itself with four different exits. Funnel Fl determines the first step of resource uptake, the voluntary feed intake (VFI), which is under a complex network of regulatory processes in farm animals (Sartin et al., 2011). Voluntary feed intake is determined by genetics, size of gastrointestinal tract

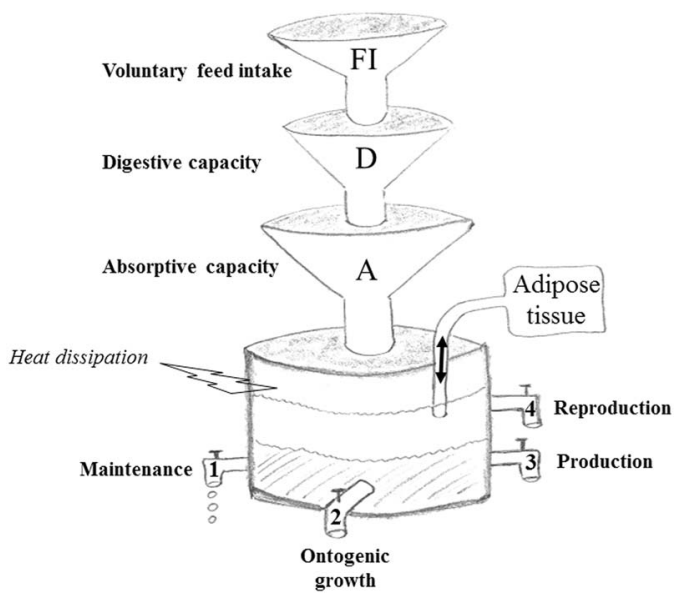

Figure 1 The barrel model modified after Rauw et al. (2008) demonstrates the process of resource allocation within the body. Voluntary feed intake (FI), digestive (D) and absorptive (A) capacity are responsible to bring the resources into the body. The resources including time for development are then allocated to maintenance (exit 1), ontogenic growth (exit 2), production (exit 3) and reproduction (exit 4). The adipose tissues are dynamical stores for energy and for endocrine regulation of whole body energy metabolism. During resource allocation a certain amount of energy is always dissipated as heat. This scheme is discussed in detail in the text. and feed quality and also by keeping conditions and welfare issues. Once food is ingested, the next funnel, digestive capacity (D) determines the availability of resources for the organism, together with funnel $A$, the absorptive capacity of the gastrointestinal tract (GIT). Both, D and $A$ are dependent on developmental ontogenic stage of the GIT, the quality and quantity of nutrients, minerals and trace elements in the diet, and the microbial community in the gut. Recently, the latter is a major topic of intensive research in human and also in farm animals (Kohl and Carey, 2016; Yang and Kweon, 2016). A proper microbiota community improved feed efficiency, growth and performance in pigs (Valeriano et al., 2016), cattle and poultry (Jewell et al., 2015; Stanley et al., 2016). Furthermore, efficiency of intestinal and pancreatic enzymes is required for a high digestive and absorptive capacity (Chambon-Savanovitch et al., 2001; Vigors et al., 2016).

\section{Maintenance}

Once nutrients are absorbed they belong to the total energy and substrate pool and stores (adipose tissues) of the body, representing the overall pool of resources. During lifetime, a certain amount of energy and substrates must be continuously used for maintenance. Maintenance is generally defined as a condition in which an animal is in nutritive equilibrium (intake $=$ loss) with neither weight gain nor loss of weight (Kleiber et al., 1945). However, maintenance is based not only on a requirement of energy but also of any essential substrate the body needs, thus equilibrium of all essentials must be established (Kleiber et al., 1945). This continuous maintenance of energy and substrate $\left(\mathrm{M}_{\mathrm{ES}}\right)$ requirement is indicated by the exit 1 of the barrel model, which is always dripping (Figure 1). $M_{E S}$ is needed for fueling basal metabolic rate, for digestive processes, for renewal of body tissues, for heat production and for immune responses to maintain BW in adults (Knap, 2008). Maintenance was more exactly defined by Kleiber et al. (1945) as a state of physiological alertness, which implicates that this is a dynamic situation of the body. Therefore, $\mathrm{M}_{\mathrm{ES}}$ cannot be a constant but depends on many factors related to genetics, nutrition and performance. The animal's size is a major factor influencing $\mathrm{M}_{\mathrm{ES}}$ (Kleiber et al., 1945). In most of the animal studies maintenance requirements were expressed as metabolizable energy (ME) for maintenance $\left(\mathrm{ME}_{\mathrm{m}}\right)$. $\mathrm{ME}_{\mathrm{m}}$ was strongly determined by organ mass and body composition as programmed by genetics in Angus cows with larger $\mathrm{ME}_{\mathrm{m}}$ needs at high protein mass, while body fat reduced $\mathrm{ME}_{\mathrm{m}}$ requirements (DiConstanzo et al., 1990). Modern dairy cows with higher efficiency to utilize dietary energy for milk production expressed an absolute increase in maintenance requirements as reflected by higher fasting heat production and increased heart rates (Moraes et al., 2015; VandeHaar et al., 2016). However, breeding for higher feed efficiency in dairy cows led to a relative decrease, a 'dilution' of maintenance, which means that a greater proportion of energy is partitioned toward milk instead of maintenance and body growth (VandeHaar et al., 2016). VandeHaar et al. (2016) concluded from the dilution of maintenance in high-yielding 
cows that maintenance requirements could be directly decreased by genetic selection. However, this can also mean that the proportion of allocated $\mathrm{M}_{\mathrm{ES}}$ is no longer matching the $\mathrm{ME}_{\mathrm{m}}$ requirements of a dairy cow. Furthermore, quality and quantity of forage feeding was modulating the energetic and substrate needs for maintenance in lactating cows (Dong et al., 2015). In laying hens, dietary protein level determined $\mathrm{ME}_{\mathrm{m}}$ (Valencia et al., 1980). In performing animals growing, lactating, egg laying - the proportion of resources for maintenance even increase to an unknown degree. Efficiency for ME use for tissue energy gain (=maintenance) was negatively correlated with efficiency of ME use for BW gain (DiConstanzo et al., 1990). However, at any metabolic situation, the resource allocation to maintenance must be conserved. If not, body structures and basal metabolic processes will be weakened and will no longer support metabolic performance sufficiently. Furthermore, maintenance requires time. Repair of tissues is resource- and timeconsuming. For example, the lactating mammary gland in high-yielding dairy cows was put out of service 6 to 8 weeks before next parturition to regenerate alveolar epithelia for the next lactation period (Zobel et al., 2015). Shortening of that time resulted in lower milk yield due to insufficient repair of mammary gland tissue, indicating that maintenance of the udder was disturbed. Turnover rates for tissues in farm animals are hardly studied, however a continuous regeneration of all body tissues can be assumed during lifetime, which needs maintenance resources. In a data synthesis approach across animal kingdom, isotope (carbon, nitrogen) turnover rates in whole body and different body tissues scaled with body mass and were influenced by body temperature (Thomas and Crowther, 2015). In humans, a 70-kg man with a given fat and protein composition needed a turnover time of 79 days to replace whole body chemical energy (Kleiber, 1975). If resources are limited, the processes of maintenance are no longer sufficient to maintain proper functional body tissues. To use the constancy of BW only as indicator for adequate maintenance is not appropriate, because high $\mathrm{BW}$ derived from rapid daily weight gain may not necessarily mean adequate development of the growing tissues and organs. Furthermore, enhanced growth and BW gain at low maintenance supply could be based on an increase of fat accretion instead of lean mass (muscle, bones). This idea will be followed up in the sections 'Limitations of resources allocation' and 'Disproportionate growth.'

\section{Juvenile growth and development}

Exit 2 in the barrel model represents the amount of resources needed for ontogenic growth of mammals and birds from birth/ hatch to adultness. Growth is determined by genetics but can be influenced by many factors such as intrauterine conditions, by endocrine dysfunction in early age and by insufficient time for postnatal maturation - all causing a resource allocation mismatch (see 'Limitations of resources allocation' and 'Disproportionate growth' sections). Physiologically, body growth most likely aimed to establish an energetically optimal body size in young animals (Hannon and Murphy, 2016).
Hannon and Murphy (2016) re-discussed the idea that maintenance energy costs $(R)$ decrease with increasing body size $(S)$ in favor of thermoregulation. $R / S$ reaches a nadir from where is rises again when body size increases above the optimal body size. At optimal body size $\mathrm{ME}_{\mathrm{m}}$ is minimal. Body growth and development is determined by genetic background but many other, mostly external factors can also influence ontogenic growth. Maternal conditions during prenatal life in utero determine the growth and development of the offspring in many farm animal species and rodent models (reviewed by Wu et al., 2006). It is strongly recommended to read this review written by Wu et al. to realize the impact of intrauterine growth and development on postnatal health and performance in livestock which is known for years. The most prominent challenge is any under- or malnourishment of the mother regarding energy, protein, minerals and trace elements, which led to intrauterine growth retardation (IUGR). In hyperprofilic sows with large litter sizes, a natural IUGR develops due to the overcrowding of the uterus and decreasing nutrient and oxygen supply for the fetuses located in the distal parts of the uterine horns (Foxcroft et al., 2006). These IUGR piglets suffered from disturbed myogenesis resulting in lower growth performance postnatally (Foxcroft et al., 2006; Rehfeldt and Kuhn, 2006), but they established a higher capacity for fat synthesis (Krueger et al., 2014). This indicated an early shift in body composition and growth with different lean: fat mass ratio. However in contrast, IUGR offspring (calves, lambs) with postnatal adequate nourishment could express catch up growth mainly based on fat accretion at juvenile age (Wu et al., 2006, Swali and Wathes, 2007). Maternal stress associated with under- or malnutrition and with any other stress factor was transferred to the offspring (Henriksen et al., 2011). The hypothalamuspituitary-adrenocortical axis was activated throughout life in these IUGR offspring (Wu et al., 2006). Furthermore, prenatal undernutrition provoked changes in behavior such as increased anxiety and reduced cognitive flexibility in sheep (Erhard et al., 2004). In poultry, the industrial production of eggs for breeding is highly prone to disturb the in-egg development of the chick; influencing factors include the health and the nutrition of the hens and the environmental conditions during artificial brooding (Dixon et al., 2016). Prenatally enhanced corticosterone levels in mother hens influenced physiology and behavior of chicks (Henriksen et al., 2011). Metabolic disturbances in glucose and lipid metabolism and insulin resistance were concomitant consequences of this metabolic programming in utero (Wu et al., 2006). Thus, an adequate management and feeding of the mothers is essential to maintain physiological ontogenic growth. Postnatal health and performance of offspring is strongly programmed by the intrauterine environment. Beside an adequate level of activation of the stress axis, thyroid hormones, vitamin $D_{3}$, IGF-1 and growth hormone are essential endocrine factors determining proper growth and development of young animals. For all processes related to ontogenic body growth and development a physiological time frame is given by the genomic structural design of each animal. Specific body structures such as the GIT in monogastric species and in ruminants, the skeletomuscular system, the mammary 
gland and the central and peripheral neuronal systems need sufficient time to develop and mature postnatally. The diet post natum, at weaning and for post-weaning rearing of young farm animals is an important determinant for development not only of the GIT but also of body tissues, for example liver and pancreas. In calves, the forestomach needed 12 to 16 weeks to be fully developed including rumen motility, salivary gland secretion and rumination activity when fed with hay and a small amount of grain (Huber, 1969). The omasum was even developing until 12 month of age in calves (Huber, 1969). There was a huge evidence form literature, that high-starch and low-fiber starter feeds negatively affect rumen development in dairy calves (Khan et al., 2016). In general, malnutrition in early life was described to have a significant negative impact on gastrointestinal development and metabolic health (He et al., 2009). Some aspects of the development appeared to be more diet-independent. At 42 to 84 days of age the ketogenic capacity of rumen epithelium was developing in sheep regardless of the diet (Lane et al., 2002). A higher weaning age ( 8 v. 6 weeks) under identical milk-feeding regimen dairy calves showed a higher rumination activity indicating a better development of rumen function due to prolonged milk nourishment (Eckert et al., 2015). In chicken, after hatching intestinal villi surface area, goblet cell numbers and mucin secretion increased during the first 8 days of life. Delayed access to feed modulated mucin secretion in chicken small intestines, implicating disturbance of protective functions of mucus (Uni et al., 2003). Ontogenic growth is a process with its own lifetime course and temporal pattern in each individual. This is strongly reflected by the huge inter-individual variation of almost all variables normally observed in animal studies. As examples, serum IGF-1 varied between 4.2 and $900.5 \mathrm{ng} / \mathrm{ml}$ in post-weaning Angus beef cattle (day 28 post weaning) (Davis and Simmen, 2000); serum glucose between 66 and $116 \mathrm{mg} / \mathrm{dl}$ in pigs (Kahn, 2005) and serum alanine concentrations between 456 and $1347 \mu \mathrm{mol} / \mathrm{l}$ in broiler chicken (Huber, own results; unpublished). 'Time' as a sensitive feature for modeling resource allocation throughout different physiological stages of an animal was already identified by Friggens and Newbold (2007). Acceleration of development and lack of maturation (immaturity) of organs and tissues due to the requested economic efficiency in animal production might be one of the most detrimental factors against extended productive life span, robustness and fitness of livestock. Thus, economic efficiency might be an apparent efficiency when considering the early life period of farm animals only.

\section{Production and reproduction}

Animal production aimed to obtain high yields in milk, meat and eggs per animal. Therefore selection for specific performance was performed since domestication of animals started thousands of years ago. Prioritizing single physiological functions needs an adequate resource allocation, which is expected to be deliverable by optimal feeding and management of the animal. Exit 3 indicates the resource allocation to production (Figure 1). However, high yields in milk, meat and eggs are often negatively correlated to fertility of farm animals. This is implicated in the barrel model by locating the exit 4 for reproduction above the production exit. Thus, when the resource allocation for production (milk, meat and eggs) is high, the filling of the barrel (=resources of the body) will never be sufficient to supply also reproduction. Furthermore, the adipose tissue - besides its role as resource store - is a tissue of high impact on reproduction, because it is a source of leptin and an indicator of size of fat stores. Leptin was described as major factor connecting energy status of an animal with its ability for reproduction by expressing a permissive effect in regulation of gonadotropin-releasing hormone neurons in the brain (Wylie, 2011). Hypothetically, selection for lean mass accretion in meat-type lines could have influenced this adipose-ovary axis leading to less fertile parent stock in pig, poultry and cattle breeding. To support this hypothesis, a correlation-based field study demonstrated a strong positive relationship between plasma leptin concentrations and fertility of ewes (Rosales Nieto et al., 2014). However, the relationship between leanness and fertility is not well studied in farm animals. Genetic selection shifted resources to the production side decreasing resource supply to reproduction and maintenance. Especially young growing animals do still have a high priority for maintenance (exit 1) and ontogenic growth (exit 2), but are physiologically less able to put resources into production and reproduction. However, growth and puberty can be pushed by nutritional regimens in nearly all farm animal species. The BW was determined as major factor for reaching puberty in human and animals. Maximal genetic growth capacity is established by high energy and protein feeding; growth rates are about $770 \mathrm{~g} /$ day in modern fattening pigs (Prunier et al., 2010), about $100 \mathrm{~g} / \mathrm{day}$ in broilers (Zuidhof et al., 2014), about $1000 \mathrm{~g} /$ day in Holstein bulls (Calo et al., 1973) and about $900 \mathrm{~g} /$ day in Holstein heifers (Van de Stroet et al., 2016), with strong variations between lines within each species. Broilers selected for growth performance had disturbed hypothalamic satiety mechanisms resulting in hyperphagia and a decreased basal metabolic rate (Zuidhof et al., 2014). Body composition depended on growth intensity and energy/ protein ratio of the diet with increasing fat accretion at higher growth rates (Dunnington and Siegel, 1996; Zuidhof et al., 2014). Thus, in meat-type species, body growth, that means protein and fat accretion is intensified and accelerated at times when ontogenic growth and development of supportive tissues (bones, cardiovascular system and skeletal muscle) should occur. Furthermore, at the same time period, proper maturation of the GIT is an essential prerequisite for any performing farm animal. Intensive rearing of young animals, as assessed by increase of BW, resulted in early puberty, and allows using the female individuals for early insemination. The first calving age in heifers was recommended to be economically valuable at about 22 to 24 months of age, the age at first service in sows at average 220 days and the start of egg-laying in laying hens at 14 weeks of age. Data on age at first calving and profitability was given by the Canadian Dairy Network (Beavers and Van Doormaal, 2015); with a profit per Holstein cow of about 
US\$ 880 gained by decreasing the current breed average (26 months) to the most profitable age at first calving (22 months). Since developmental periods before onset of performance are expensive in all farm animal species, similar calculations with high profit at early use could be performed. Furthermore, early production performance of heifers aimed to generate a high first lactation milk yield; and of primiparous sows a large litter size (high prolificacy) is intended. Laying hens should provide at least 300 eggs/laying period. Early laying start will increase the turnover rate of hen cohorts in the poultry facility thereby improving economic output. However, under early performance conditions, maturation of the body, of the supportive tissues and of the endocrine and neuronal regulation processes might not be adequately developed. These discussed physiological and pathophysiological pathways involved in resource allocation for maintenance, ontogenic growth and production/ reproduction were summarized in Figure 2 . By acceleration of growth, animals were created which have a low plasticity. In terms of modeling, plasticity was described as 'the rate of change in the level of a single trait when measured across

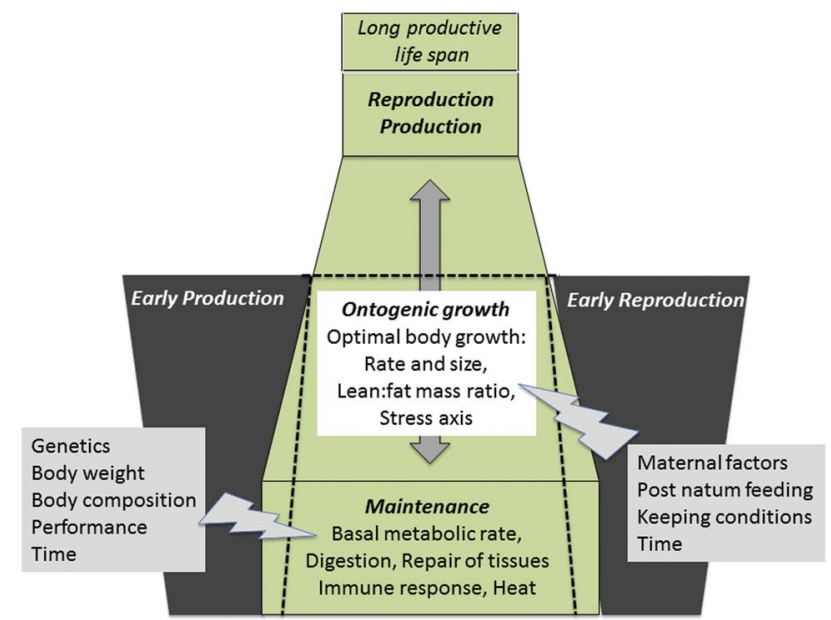

Figure 2 Summary of important physiological pathways involved in resource allocation. A proper allocation of resources during growth and development, productive life and reproductive periods is essential for a farm animal to stay healthy and fertile despite high performance in milk, meat or eggs. Resource allocation to maintenance is suggested as indispensable basis for the whole productive life span. This is a dynamic process; major factors modulating resource allocation to maintenance are indicated with the gray flash (right side). Ontogenic growth based on stable resource fluxes to maintenance leads to optimal body size and metabolic tissues and organs, which can carry the burden of both, production and reproduction and enable a long productive life span. The gray arrow indicates the developmental time, which is programmed for each individual; any shortening of this time is detrimental for the optimal body growth. Ontogenic growth is also modulated by different factors as indicated by the gray flash (left side). Early in life production or reproduction is a declared goal of modern animal production to decrease raising costs. However, the earlier this is requested, the lower is the maturity of the organism because these features take away resources from maintenance and ontogenic growth (indicated by the black dotted lines). This causes disproportionate growth, which resulted in failure to adapt to production/reproduction and an inability to cope to inverse environments (low metabolic plasticity). It must be the goal of future research to determine the quantitative aspects of resource allocation to maintenance and ontogenic growth in terms of energy, substrates and time. different environments'; and animal with low plasticity will maintain its genetically driven single performance trait at the expense of other life functions (Friggens and Newbold, 2007). Low plasticity animals selected in an abundant environment might be unable to cope with less ideal environment and might face a substantial reduction in fitness (Friggens and Newbold, 2007). An adequate management and feeding is not always deliverable at field conditions, thus under these conditions, high merit farm animals may suffer from external limitations of resources.

\section{Limitations of resource allocation}

The idea about limitations of resource allocation is very old. Already the ancient Greek philosopher and researcher Aristotle (384 to 322 BCE) stated the idea of physiological limitation. Later, Goethe expressed 'the budget of nature is fixed but she is free to dispose of particular sums by any appropriation that may please her. In order to spend on one side, she is forced to economize on the other side' (Rauw, 2008). Prinzinger (2005) disclaimed that 'it is not necessary that living organisms should age and die as long as it retains the ability to repair (damaged cells) and renew (defective cells).' The latter reflects the strong necessity for a proper maintenance metabolism in all tissues as prerequisite for a long and healthy life. However, the budget of resources is limited; thus allocation is the basal mechanism by which a proper shift of energy and nutrients to maintenance can be made. Especially this limitation of resource allocation most likely occurs when young immature animals are early pushed into productive life. The reasons why resource allocation reaches its limitation are manifold. External factors such as inadequate management and feeding led to absolute resource limitations. However, any disturbances in ontogenic growth (as described in the 'Resources and resource allocation' section), the genetically determined acceleration of BW gain and an early use in reproduction with subsequent performance (milk yield, litter size) promotes the risk of an individual to reach the limits of resource allocation. This means, resources are no longer provided for physiological healthy development and performance but are shifted to selected body processes associated with performance. However, thereby $M_{E S}$ requirements are neglected. Reduction in maintenance leads to a loss of the individual's adaptive capacity to cope with (genetically) requested performance and to a loss of the individual's flexibility to cope with suboptimal environmental conditions (Knap and Rauw, 2008), features which contribute to the physiological balance of an individual. To clarify the limitations of resource allocation, the broilers and laying hens used in poultry meat and egg production, respectively, will be used as examples for animals, which exceeded their physiological balance due to limitation and mismatch of resource allocation. Poultry is a good example due to their rapid generation interval, thus breeding success is obtained very quickly. Physiologically, a young chick is genetically imprinted to allocate its resources to maintenance and ontogenic growth after (and most likely already before) hatch. However, genetic selection for lean mass 
accretion and breast muscle proportion pushes the modern young broiler chick into production from the first day of life. Feeding and management was optimized to match the requirements of broiler lines according to their genetic growth potential. Growth rate is the single variable during fattening, which is used to record success of production, which is critical (see the 'Resources and resource allocation' section, Buzala et al., 2015). According to the barrel model in Figure 1, this means that exit 3 is already widely open immediately after hatch for selective muscle growth. Higher growth rate may also open exit 2 more than physiologically determined while resource flux (energy, nutrients and time) via exit 1 for maintenance is most likely reduced due to the limitation of resource availability. This was confirmed by findings in broiler embryos, which had a lower heat production already in ovum and a lower resting metabolic rate within the first week of life compared to slowly growing layer embryos and layer chicks (Konarzewski et al., 2000, Sato et al., 2006). The short but intensive productive life of broilers most likely cause a strong limitation of resource allocation to maintenance and ontogenic growth. In laying hens, the intensive egg production is a continuous challenge for the energy and substrate metabolism, starting early in life (Buzala et al., 2015). In these laying hens, exit 4 is widely open (Figure 1). Since exit 4 for reproduction is above exit 3 for production, this should indicate that the resource requirements for egg-laying is at least as high as for massive growth but maybe even higher. Again, resource flux into maintenance (exit 1) is reduced under these conditions. This leads to morphological constraints and functional conflicts in individual broiler and layer chicken. Immature supportive tissues and cellular functions are the result of the limitations of resource allocation and resource allocation mismatch. In laying hens, the fatty liver hemorrhagic syndrome (FLHS) was described, which is a severe metabolic disorder. Symptoms are intracoelomic fat accumulation, hepatic lipidosis, hepatic tissue and capsule rupture and bleedings within the liver and into the body cave (Trott et al., 2014). Histologically, the liver expresses fat vacuoles in the hepatocytes in many but not in all hens. But a lack of reticulin fibers (collagen type III) was observed in the liver of nearly all hens with FLHS (Trott et al., 2014). It is not clear so far, if this lack of collagen type III is a consequence of the syndrome or the initial cause. It was discussed that lipid accumulation was the cause of the reticulin fiber disruption (Walzem et al., 1993), however this syndrome also occurred in livers without any fat accumulation. Hence, according to the resource allocation theory, reduction in maintenance leads to immature tissues. If liver tissue structure is not well developed (e.g. sufficient amount of collagen fibers to stabilize and organize hepatic tissue) due to early and high performance of laying hens, then these livers are most likely prone to fail adaptation to performance. Rupture of vessels and liver capsule indicated impaired strength of supportive tissue components such as the extracellular matrix (ECM) and collagen dystrophy. Another disorder associated with collagen dystrophy and lack of sufficient vascularization is the tibial dyschondroplasia (TD) in bone growth plates of rapidly growing broiler chicken, a disorder with disturbed development of bone tissue structure (Leach and Monsonego-Ornan, 2007).
The lesion was characterized by avascular cartilage, lipid accumulation within the cells and necrosis; the latter are typical signs of energy depletion. As cellular origin of lack of ECM, lack of vessels, nutrient and oxygen depletion and consequently, chondrocyte necrosis, endoplasmatic reticulum (ER) stress was discussed, which led to intracellular retention of ECM proteins (collagen $\mathrm{X}$ ) in chondrocytes (Leach and Monsonego-Ornan, 2007). Furthermore, it was suggested that activity of matrix metalloproteinases in TD lesions was reduced, thus the turnover of cartilage tissue failed (Farquharson and Jefferies, 2000). Again, it is not known if failure of supportive components such as ECM is the consequence or the cause (=immaturity of ECM) of TD. Most likely, rapid growth led to insufficient maturation of the metaphyseal region of the os tibiotarsus and os tarsometatarsus due to shortening in developmental time and reduction in resources for maintenance and proper ontogenic growth. This leads to weakened bones, bone deformation and lameness in poultry. Other reasons for locomotory and metabolic problems in modern poultry are associated with the health of muscle tissues. More recently, a new myopathy with increasing prevalence occurred in poultry industry, the wooden breast disease in fast growing, high genetic merit broilers. The broilers develop a firm, pale and dry breast muscle flesh during fattening, often in combination with white striping. This novel muscle myopathy is associated with poor meat quality, which leads to high economic losses in poultry industry. Furthermore, it is an animal welfare issue. The lesions of the musculus pectoralis major were characterized by lack of vascularization, myocyte necrosis, muscular fibrosis (collagenrich connective tissue) and inflammatory infiltration (Sihvo et al., 2014). The etiology of this disease is unknown so far. This myodegenerative disorder - among other myopathies in broilers - might be based on oxidative stress in the very rapidly growing breast muscle. Especially the superficial layer of the muscle was affected, which is physiologically less vascularized and mostly consists of white fibers (Kranen et al., 1999). In a transcriptomics study of affected and non-affected broiler breast muscles genes indicating hypoxia, oxidative stress, mitochondrial dysfunction and inflammation-driven reorganization of tissue were identified to characterize wooden breast myopathy (Mutryn et al., 2015; Abasht et al., 2016). In the context of resource allocation theory, although resources were maximally allocated to the breast muscle, supportive components (vascularization, mitochondria) of the breast muscle were not adequately developed due to the rapid growth rate and reduction in resource allocation to maintenance. Given that genetically driven resource allocation to breast muscle growth was maximized, wooden breast myopathy could indicate a limit of genetically selected growth performance, that is the breeding limit. A further example for insufficient maturation of tissues was demonstrated by Voillet et al (2014) in piglets. Piglet postnatal mortality within the first $96 \mathrm{~h}$ rose significantly during the last decades which could be based on immaturity. Physiological maturity was discussed to be of high importance for early survival after birth. Immaturity of fetal muscles of Large White piglets was identified as underlying pathomechanism by a transcriptomic approach in piglets of 
Huber

genotypes with low (Large White) and high (Meishan) postnatal survival. Especially genes belonging to pathways of extracellular matrix and collagen and of energy metabolism and mitochondrial function were differently expressed (Voillet et al., 2014). This indicates that dependent on genotype, high performance is associated with immaturity of structural and functional components of tissues; and this is already relevant in the prenatal period.

\section{Disproportionate growth}

The question arises why the breast muscle is affected by hypoxia, oxidative stress and inflammation. Most likely, it is too large in respect to other body parts and organs. When parts of the body were larger or smaller than physiological, the body growth is disproportionate. Disproportionate growth is based on resource allocation mismatch and acts against the genetically determined scaling rules for body and organ proportions. Furthermore, genetic selection to single performance traits affected the respective organ and tissue anatomy and micromorphology, resulting in disproportionate growth also on cellular and within-tissue level. Selection for high feed intake in high-performing farm animals may exacerbate this condition. High feed intake accelerates growth, and thereby resource allocation mismatch can occur due to lack of time. The process of maturity needs time, maybe different amounts of time for certain structures (e.g. ECM) and functions (e.g. mitochondria and fatty acid oxidation), although the tissue is growing to its final, genetically determined size. The larger it is in size or the more metabolically active it is the more detrimental this lack of time for maturation will be. Thus again, growth itself measured by BW gain is not a good indicator of maturity. Another side effect was the enhanced proportion of fat accretion with higher BW in chicken based on high voluntary feed intake and reduced lipolytic capacity (Dunnington and Siegel, 1996). Thus, selection for high feed intake creates individuals prone to accrete fat disproportionately, resulting in obesity. The breast muscle of broilers is allometrically growing by increasing numbers and sizes of white myofibers (Rehfeldt and Kuhn, 2006). Maximizing the breast muscle yield in broilers to about $20 \%$ and more of BW resulted in decreases in the relative weights of heart and lungs (negative allometrical growth), while the intestine was larger with a highly developed absorptive capacity. The disproportionality regarding the respiration system was even more obvious by a relative low size of musculus externus obliquus (a major respiratory muscle which moves the sternum during respiration) and a slow ossification of components of the respiratory skeleton (ribs, sternum, processus uncinatus) (Tickle et al., 2014). Lack of vascularization in breast muscle, as seen in wooden breast myopathy, and in bones, as seen in TD, may also indicate disproportionate growth, with less developed supportive components such as the ECM (Leach and Monsonego-Ornan, 2007; Sihvo et al., 2014). Since these broiler chickens outgrow their respiratory capacity, these morphological constraints have detrimental consequences for the whole organism. Acceleration of growth in broilers led to an increase in body mass from $40 \mathrm{~g}$ to $4000 \mathrm{~g}$ in about 8 weeks. Concomitantly, the cardiac output rate had to increase from $8 \mathrm{ml} / \mathrm{min}$ to $800 \mathrm{ml} / \mathrm{min}$ to maintain a proper oxygen supply for the body (Wideman et al., 2007). However, relatively smaller hearts and lungs, a physiologically constant lung volume and lung capillary capacity, an inhibition of respiratory movements of the thorax due to the large breast muscle and the immature respiratory skeleton and muscles led to increased resistance against blood flow and to inhibition of gas exchange. Consequently, a right heart hypertrophy developed leading to ascites. The transudate fluid in the body cave inhibited the air sac inflation. Reduced blood and air flows in the respiratory system diminished the oxygen saturation of the arterial blood, which is detrimental especially for the rapidly growing breast muscle and also any other body organ and tissue. Sudden death is the consequence of this pulmonary hypertension syndrome (ascites syndrome) in broilers (Wideman et al., 2007; Kalmar et al., 2013). This resource allocation mismatch in broilers can be also assessed for other species. Rapidly growing fattening pigs and bull calves and fastened rearing of heifer calves most likely promote similar disproportionate growth. Modern pigs had larger muscles, more white fibers and relatively smaller hearts than the older strains (Dämmrich, 1987). Furthermore, genetic selection appears to induce delayed muscular development in piglets (Voillet et al., 2014). High-yielding dairy cows are prone to put all resources into milk thereby increasing the risk to suffer from chronic systemic inflammation and associated metabolic disorders (Bradford et al., 2015). However, due to the longer production intervals and less selection for growth of single muscles it takes a longer time for developing unfavorable conditions or at least they are less visible. However, high losses in the rearing period of calves and piglets might be caused by a reduction of resource allocation to maintenance and ontogenic growth. Selection for rapid udder growth and development may implicate a high risk for resource allocation mismatch and disproportionate growth in heifers. Anyway, disproportionate growth provoked by resource allocation mismatch in early life could accumulate to a lifethreatening condition, which finally leads to organ and cell failure, most likely by oxidative stress, mitochondrial dysfunction and systemic inflammation. The consequence is not only an economic issue but also an important animal welfare issue.

\section{Summary and conclusions}

Resources are nutrients, energy and developmental time. An adequate resource allocation to maintenance is the most important process to grow and develop proper body structures, which are essential for high performance in farm animals. Any resource allocation mismatch leads to disproportionate growth on whole body, on tissue and cell level. If livestock industry continues to use high genetic merit animals then an adequate management is always required. These animals lost the 
capacity to cope with disadvantageous keeping and feeding conditions. Furthermore, if a healthy productive life span or a long and healthy productive life span is intended, all animals need a resource allocation which matches maintenance requirements. The most prominent factor, which should be considered in developing new strategies for livestock production is time for maturation. Slowing down the juvenile development to maintain adequate resource allocation to maintenance and ontogenic growth will result in animals with mature organs and tissues, which can carry the burden of high performance.

\section{Acknowledgment}

This review is based on an invited presentation at the 67th Annual Meeting of the European Association for Animal Production held in Belfast, United Kingdom, August 2016.

\section{References}

Abasht B, Mutryn MF, Michalek RD and Lee WR 2016. Oxidative stress and metabolic perturbations in wooden breast disorder in chickens. PLoS One 11, e0153750.

Beavers L and Van Doormaal B 2015. Age at first calving and profitability. Canadian Dairy network. Retrieved on 6 June 2017 from https://www.cdn.ca/document.php? id $=413$.

Bradford BJ, Yuan K, Farney JK, Mamedova LK and Carpenter AJ 2015. Invited review: inflammation during the transititon to lactation: new adverntures with an old flame. Journal of Dairy Science 98, 6631-6650.

Buzala M, Janicki B and Czarnecki R 2015. Consequences of different growth rates in broiler breeder and leyer hens on embryogenesis, metabolism and metabolic rate: a review. Poultry Science $94,728-733$.

Calo LL, McDowell RE, Van Vleck LD and Miller PD 1973. Parameters of growth of Holstein-Frisian bulls. Faculty Papers and Publications in Animal Science, Paper No. 331. Retrieved on 17 January 2017 from http://digitalcommons.unl. edu/animalscifacpub/331.

Chambon-Savanovitch C, Felhines C, Walrand S, Raul F, Zarrabian S, Meunier MT, Farges MC, Cynober L and Vasson MP 2001. A pancreatic extract-rich diet improved the nutritional status of aged rats. Journal of Nutrition 131, 813-819.

Dämmrich K 1987. Organ change and damage during stress - morphological diagnosis. In Biology of stress in farm animals: an integrated approach (ed. PR Wiepkema and PWM van Adrichem), pp. 71-81. Martinus Nijhoff, Dordrecht, the Netherlands.

Davis ME and Simmen RCM 2000. Genetic parameter estimates for serum insulin-like growth factor 1 concentration and carcass traits in Angus beef cattle. Journal of Animal Science 78, 2305-2313.

DiConstanzo A, Meiske JC, Plegge D, Peters TM and Goodrich RD 1990. Withinherd variation in energy utilization for maintenance and gain in beef cows. Journal of Animal Science 68, 2156-2165.

Dixon LM, Sparks NHC and Rutherford KMD 2016. Early experience matter: a review of the effects of prenatal environment on offspring characteristics in poultry. Poultry Science 95, 489-499.

Dong LF, Ferris CP, MyDowell DA and Yan T 2015. Effects of diet forage proportion on maintenance energy requirement and the efficiency of metabolizable energy use for lactation dairy cows. Journal of Dairy Science 98 , 8846-8855.

Douhard F, Tichit M, Amer PR and Friggens NC 2014. Synergy between selection for production and longevity and the use of extended lactation: insights from a resource allocation model in a dairy goat herd. Journal of Animal Science 92, 5251-5266.

Dunnington EA and Siegel PB 1996. Long-term divergent selection for eight-week body weight in white Plymouth rock chickens. Poultry Science 75, 1168-1179.

Eckert E, Brown HE, Leslie KE, DeVries TJ and Steele MA 2015. Weaning age affects growth, feed intak, gastrointestinal development, and behavior in Hostein calves fed an elevated plane of nutrition during the preweaning stage. Journal of Dairy Science 98, 6315-6326.
Erhard HW, Boissy A, Rae MT and Rhind SM 2004. Effects of prenatal undernutrition on emotional reactivity and cognitive flexibility in adult sheep. Behavioral Brain Research 151, 25-35.

Farquharson C and Jefferies D 2000. Chondrocytes and longitudinal bone growth: the development of tibial dyschondroplasia. Poultry Science 79, 994-1004.

Foxcroft GR, Dixon WT, Novak S, Putman CT, Town SC and Vinsky MDA 2006. The biological basis for prenatal programming of postdantal performance in pigs. Journal of Animal Science 84 (E.suppl.), E105-E112.

Friggens NC and Newbold JR 2007. Towards a biological basis for predicting nutrient partitioning: the dairy cow as an example. Animal 1, 87-97.

Glazier DS 2008. Resource allocation pattern. In Resource allocation theory applied to farm animal production (ed. WM Rauw), pp 22-43. CABI Publishers, Oxfordshire, UK. http://www.inasp.info/en/network/publishers/16/; doi: 10.13140/RG.2.1.1810.9206.

Hannon BM and Murphy MR 2016. Toward a theory of energetically optimal body size in growing animals. Journal of Animal Science 94, 2532-2541.

Henriksen R, Rettenbacher $S$ and Groothuis TGG 2011. Prenatal stress in birds: pathways, effects, function and perspectives. Neuroscience and Biobehavioral Reviews 35, 1484-1501.

He Z, Sun Z, Liu S, Zhang Q and Tan Z 2009. Effects of early malnutrition on mental system, metabolic syndrome, immunity and the gastrointestinal tract. Journal of Veterinary Medical Sciences 71, 1143-1150.

Huber JT 1969. Development of the digestive and metabolic apparatus of the calf. Journal of Dairy Science 52, 1303-1315.

Jewell KA, MyCormick CA, Odt CL, Weimer PJ and Suen G 2015. Ruminal bacteria community composition in dairy cows is dynamic over the course of two lactations and correlates with feed efficiency. Applied Environmental Microbiology 81, 4697-4710.

Kahn CM 2005. Merck veterinary manual, 9th edition. Merck \& Co, Whitehouse Station, NJ.

Khan MA, Bach A, Weary DM and von Keyserlingk MAG 2016. Invited review: transitioning from milk to solid feed in dairy heifers. Journal of Dairy Science 99 , 885-902.

Kalmar ID, Vanrompay D and Janssens GPJ 2013. Broiler ascites syndrome: collateral damage from efficient feed to meat conversion. Veterinary Journal 197, 169-174.

Kleiber M 1975. Metabolic turnover rate: a physiological meaning of the metabolic rate per unit body weight. Journal of Theoretical Biology 53, 199-204. Kleiber M, Regan WM and Mead SW 1945. Measuring food values for dairy cows. Hilgardia 16, 511-517.

Knap PW 2008. Allocation of resources to maintenance. In Resource allocation theory applied to farm animal production (ed. WM Rauw), pp 110-129. CABI Publishers, Oxfordshire, UK. http://www.inasp.info/en/network/publishers/16/; doi: 10.13140/RG.2.1.1810.9206.

Knap PW and Rauw WM 2008. Selection for high production in pigs. In Resource allocation theory applied to farm animal production (ed. WM Rauw), pp 210-229. CABI Publishers, Oxfordshire, UK. http://www.inasp.info/en/network/publishers/16/; doi: 10.13140/RG.2.1.1810.9206.

Kohl KD and Carey HV 2016. A place for host-microbe symbiosis in the comparative physiologist's toolbox. Journal of Experimental Biology 219, 3496-3504.

Konarzewski M, Gavin A, McDevitt R and Wallis IR 2000. Metabolic and organ mass responses to selection for high growth rates in the domestic chicken (Gallus domesticus). Physiological and Biochemical Zoology 73, 237-248.

Kranen RW, van Kuppevelt TH, Goedhart HA, Veerkamp CH, Lambooy E and Veerkamp JH 1999. Hemoglobin and myoglobin content in muscles of broiler chickens. Poultry Science 78, 467-476.

Krueger R, Derno M, Goers S, Metzler-Zebeli BU, Nuernberg G, Martens K, Pfuhl R, Nebendahl C, Zeyner A, Hammon HM and Metges C 2014. Higher body fatness in intrauterine growth retarded juvenile pigs is associated with lower fat and higher carbohydrate oxidation during ad libitum and restricted feeding. European Journal of Nutrition 53, 583-597.

Lane MA, Baldwin RL and Jesse BW 2002. Developmental changes in ketogenic enzyme gen expression during sheep rumen development. Journal of Animal Science 80, 1538-1544.

Leach RM and Monsonego-Ornan E 2007. Tibial dyschondroplasia 40 years later. Poultry Science 86, 2053-2058. 
Huber

Moraes LE, Kebreab E, Strathe AB, Dijkstra J, France J, Casper DP and Fadel JG 2015. Multivariate and univariate analysis of energy balance date from lactating dairy cows. Journal of Dairy Science 98, 4012-4029.

Mutryn MF, Brannick WM, Fu W, Lee WR and Abasht B 2015. Characterization of a novel chicken muscle disorder through differential gene expression and pathways analysis using RNA-sequencing. BMC Genomics 16, 399.

Puillet L, Reale D and Friggens NC 2016. Disentangling the relative roles of resource acquisition and allocation on animal feed efficiency: insights from a dairy cow model. . Genetics Selection Evolution 48, 72.

Prinzinger R 2005. Programmed ageing: the theory of maximal metabolic scope. EMBO Reports 6, S14-S19.

Prunier A, Heinonen M and Quesnel H 2010. High physiological demands in intensively raised pigs: impact on health and welfare. Animal 4, 886-898.

Rauw WM 2008. Life history theory. In Resource allocation theory applied to farm animal production (ed. WM Rauw), pp 1-21. CABI Publishers, Oxfordshire, UK. http://www.inasp.info/en/network/publishers/16/; doi: 10.13140/ RG.2.1.1810.9206

Rehfeldt C and Kuhn G 2006. Consequences of birth weight for postnatal growth performance and carcass quality in pigs as related to myogenesis. Journal of Animal Science 84 (E.suppl.), E113-E123.

Rosales Nieto CAR, Thompson AN, Macleay CA, Briegel JR, Hedger MP, Ferguson MB and Martin GB 2014. Relationships among body composition, circulating concentrations of letin and follistatin, and the onset of puberty and fertility in young female sheep. Animal Production Science 151, 148-156.

Sartin JL, Whitlock BK and Daniel JA 2011. Triennial growth symposium: neural regulation of feed intake: Modifications by hormones, fasting, and disease. Journal of Animal Science 89, 1991-2003.

Sato M, Tachibana T and Furuse M 2006. Heat production and lipid metabolism in broiler and layer chickens during embryonic development. Comparative Biochemistry and Physiology Part A 143, 382-388.

Savieto D, Friggens NC and Pascual JJ 2015. Reproductive robustness differs between generalist and specialist maternal rabbit lines: the role of acquisition and allocation of resources. Genetics Selection Evolution 47, 2.

Sihvo HK, Immonen K and Puolanne E 2014. Myodegeneration with fibrosis and regeneration in the pectoralis major muscle of broilers. Veterinary Pathology 51 619-623.

Stanley D, Hughes RJ, Geier MS and Moore RJ 2016. Bacteria within the gastrointestinal tract microbiota correlated with improved growth and feed conversion challenges presented for the identification of performance enhancing bacteria. Frontiers in Microbiology 7, 187.

Swali A and Wathes DC 2007. Influence of primiparity on size at birth, growth, the somatotrophic axis and fertility in dairy heifers. Animal Reproduction Science 102, 122-136.

Thomas SM and Crowther TW 2015. Predicting rates of isotopic turnover across the animal kingdom: a synthesis of existing data. Journal of Animal Ecology 84, 861-870.

Tickle PG, Paxton H, Rankin JW, Hutchinson JR and Codd JR 2014. Anatomical and biomechanical traits of broiler chicken across ontogeny. Part I. Anatomy of the musculoskeletal respiratory apparatus and changes in organ size. PeerJ 2, e432.
Trott KA, Giannitti F, Rimoldi G, Hill A, Woods L, Barr B, Anderson M and Mete A 2014. Fatty liver hemorrhagic syndrome in the backyard chicken: a retrospective histopathologic case series. Veterinary Pathology 5, 787-795.

Uni Z, Smirnov A and Sklan D 2003. Pre- and posthatch development of goblet cells in the broiler small intestine: effect of delayed access to feed. Poultry Science 82, 320-327.

Valencia ME, Maiorino PM and Reid BL 1980. Energy utilization in laying hens. III Effect of dietary protein level at 21 and 32 C. Poultry Science 59, 2508-2513.

Valeriano VDV, Balolong MP and Kang DK 2016. Probiotic roles of Lactobacillus spp. In swine: insights from gut microbiota. Journal of Applied Microbiology 122, 554-567.

VandeHaar MJ, Armentano LE, Weigel K, Spurlock DM, Tempelman RJ and Veerkamp R 2016. Harnessing the genetics of the modern dairy cow to continue improvements in feed efficiency. Journal of Dairy Science 99, 4941-4954.

Van De Stroet DL, Calderon Diaz JA, Stalder KJ, Heinrichs AJ and Dechow CD 2016. Association of calf growth traits with production characteristics in dairy cattle. Journal of Dairy Science 99, 8347-8355.

Vigors S, Sweeney T, 0’Shea CJ, Kelly AK and O’Doherty JV 2016. Pigs that are divergent in feed efficiency, differ in intestinal enzyme and nutrient transporter gene expression, nutrient digestibility and microbial activity. Animal 10 1848-1855.

Voillet V, SanCristobal M, Lippi Y, Martin PGP, lannuccelli N, Lascor C, Vignoles F, Billon $Y$, Canario $L$ and Liaubet L 2014. Muscle transcriptomic investigation of late fetal development identifies candidate genes for piglet maturity. BMC Genomics 15, 797.

Walzem RL, Simon C, Morishita T, Lowenstine L and Hansen RJ 1993. Fatty liver hemorrhagic syndrome in hens overfed a purified diet: selected enzyme activities and liver histology in relation to liver hemorrhage and reproductive performance. Poultry Science 72, 1479-1491.

Weiner J 1992. Physiological limits to sustainable energy budgets in birds and mammals: ecological implications. Trends in Ecology and Evolution 7, 384-388. Wideman RF, Chapman ME, Hamal KR, Bowen OT, Lorenzoni AG, Erf GF and Anthony NB 2007. An inadequate pulmonary vascular capacity and susceptibility to pulmonary arterial hypertension in broilers. Poultry Science 86, 984-989.

Wu G, Bazer FW, Wallace JM and Spencer TE 2006. Invited review: intrauterine growth retardation: implications for the animal sciences. Journal of Animal Science 84, 2316-2337.

Wylie ARG 2011. Leptin in farm animals: where are we and where can we go? Animal 5, 246-267.

Yang JY and Kweon MN 2016. The gut microbiota: a key regulator of metabolic diseases. BMB Reports 49, 536-541.

Zobel G, Weary DM, Leslie KE and von Keyserlingk MAG 2015. Invited review: cessation of lactation: effects on animal welfare. Journal of Dairy Science 98 8263-8277.

Zuidhof MJ, Schneider BL, Carney VL, Korver DR and Robinson FE 2014. Growth, efficiency, and yield of commercial broilers from 1957, 1978, and 2005. Poultry Science 93, 1-13. 